\title{
CAPTURING MOBILE COLLABORATION THROUGH THE TRIANGULATION OF QUALITATIVE AND QUANTITATIVE DATA
}

\author{
Peter Ilic \\ University of Aizu, Center for Language Research, School of Comp. Sc \& Engineering, \\ Tsuruga, Ikki-machi, Aizu-Wakamatsu, Fukushima, 965-8580, Japan
}

\begin{abstract}
This paper reflects on an attempt to introduce smartphones into a blended learning context and highlights several methodological considerations relevant to the collection of mobile data. While mixed methods research is now common, using this approach for investigating the challenges of mobile data collection is not as common. This study employed a mixed method longitudinal exploratory multiple case study design. The study collected qualitative and quantitative data on student interactions within a yearlong series of collaborative language learning activities. This paper describes the methodological issues that emerged during the planning and implementation of the study. The participants were undergraduate students studying English translation at a four-year private university in Tokyo, Japan. This paper adds to the knowledge of employing mixed methodology design for mobile data collection and analysis. In particular, the advantages of incorporating Multidimensional Scaling (MDS) analysis with qualitative data. The results suggest that separate forms of data collected at similar frequencies and times that are then triangulated provided an effective methodology for studying collaborative learners in a highly mobile context. This can be seen as evidence for the inclusion of various data collection cycles of both qualitative and quantitative type within a single mobile learning research study. The discussion section includes a summary of the findings, limitations, and possibilities for furthering the study topic.
\end{abstract}

\section{KEYWORDS}

Mobile Learning, Collaboration, Triangulation, Mixed Methodology, MDS

\section{INTRODUCTION}

The dramatic impact of smartphone technology on society suggests the potential for a similarly significant effect on education. This study explores a specific sector of education affected by this technology; it focuses on the impact on students from integrating mobile phones in collaborative language learning activities at the university level. The object of the research study 


\section{CAPTURING MOBILE COLLABORATION THROUGH THE TRIANGULATION OF}

QUALITATIVE AND QUANTITATIVE DATA

designed around the following methodology was to add to the understanding of this interaction, such as, how the affordances mobile technology offers, like anytime and anywhere communication and data gathering, affect student approaches to the activities.

This study employed a mixed method longitudinal exploratory multiple case study design. Mixed methodology because the study collected qualitative and quantitative data on student interactions. Longitudinal since the study took place over one academic year and included a yearlong series of collaborative language learning activities. The case study was exploratory in the sense that the research questions were broad and open to the discovery of unanticipated results. The case study design is multiple in the sense that it was subdivided into four independent but identical smaller class size case studies which were brought together for the final analysis. This paper describes the methodological issues that emerged during the planning and implementation of the study as well as a summary of the key findings. This analysis will be valuable to researchers, instructors, and administrators engaged in applying smartphones in a pedagogical context. While the context is limited to a university, the recommendations may still be transferred to diverse situations where smartphones are common, and a well-developed mobile infrastructure exists.

The study demonstrates that valuable results can be gained from such an approach and that the strength of the findings can be increased through triangulation. Also, the design of the data collection frequency was shown to have a relationship with the pattern of triangulation. This finding may be of value to other researchers during the research design phase and the coding phase.

The first section includes study design, participant selection, ethics, validity and reliability. The second section discusses data collection methods including website logs, e-journals, artefacts from assignments, and interviews. The third section discusses data analysis both qualitative and quantitative. The fourth section includes a discussion, limitations with the study, and key findings. Then finally, the conclusion presents the closing discussion of this paper, introducing possibilities for furthering the study topic.

\section{LITERATURE REVIEW}

This review of the literature gives an overview of the research methodologies in the field of mobile learning. Hwang et al. (2011) report that the pace of publication of mobile and ubiquitous learning articles increased to nearly four times from 2008 to 2010. Wu et al. (2012) found the frequency of publication increased from low-to-mid single digits from 2003 to 2006, to low double-digits from 2007 to 2009, and suddenly jumped to 106 in 2010. The journals consistently cited for mobile and ubiquitous learning are the British Journal of Educational Technology, Computers and Education, Educational Technology \& Society, Educational Technology Research \& Development, Journal of Computer Assisted Learning and Innovations in Education and Teaching International (Hwang and Tsai, 2011).

There is a deep variety of methodologies employed in mobile research. Wu et al. (2012) reviewed 164 papers published from 2003 to 2010 from the perspective of methodology in relation to four research purposes; purpose one being mobile learning systems and the evaluation of their effectiveness, purpose two being designs of mobile systems and the evaluation of their effectiveness, purpose three is investigating the affective domain during mobile learning, and purpose four is designing a mobile system for learning. They discovered that for purpose one, researchers primarily relied on surveys ( 26 studies), followed by experimental research methods (20) and descriptive methods (7). For purpose two, experimental research methods were used most often (4), followed by surveys (2), descriptive methods (1) and observation (1). 
IADIS International Journal on WWW/Internet

For purpose three, only two methodologies were used: surveys (6) and interviews (1). For purpose four, surveys were the most commonly used methodology (16), followed by experimental research methods (14), descriptive methods (8), case studies (2) and observation (1). Similarly, Baran (2014) found that for mobile learning in the teacher education literature most methodologies were case studies or mixed method. Data sources they report included questionnaires, interviews, blogs, recordings, observations, journals, artefacts, usage data, and audio and video transcripts.

When considering learning domains in studies, Hwang et al. (2011) identified that from 2001 to 2010 most studies involved no learning domain, instead, they concentrated on the investigation of motivations, perceptions, and attitudes of students towards mobile and ubiquitous learning. In the same study (Hwang and Tsai, 2011), of those investigations that focused on learning domains, the most common were 'engineering (including computers),' followed by 'arts and language,' 'science,' 'social science,' 'mathematics,' and other learning domains. In addition, Wu et al. (2012) found that in 164 papers published from 2003 to 2010, studies of mobile learning for educational purposes focused most frequently on applications in the professions and applied sciences (29\%), followed by humanities (20\%), formal sciences $(16 \%)$, social sciences $(4 \%)$ and natural sciences (3\%). In sub-disciplines, languages and linguistics courses were the most common focus $(17.05 \%)$, followed by computer science $(13.07 \%)$, health sciences $(10.23 \%)$, environmental studies and forestry $(10.23 \%)$, physics $(2.27 \%)$, business $(2.27 \%)$, and journalism, media studies, and communication $(2.27 \%)$.

In their review of 164 studies from 2003 to 2010, Wu et al. (2012) looked at the context of the studies: formal education, non-formal education, and informal education. They found that in formal education contexts, higher education institutions favoured mobile phones (34 studies), followed by PDAs (30) and laptops (7), while PDAs were more commonly used in elementary schools (18). In non-formal education contexts, mobile phones were still predominant (5), but the frequency of use was lower than in formal educational use in higher education institutions. Similarly, mobile phones were employed in informal education (6). PDAs and other devices and mobile services (e.g., digital music players, iPods, cameras, podcasts, GPS devices, and satellite TV) were applied in all three educational contexts but with low frequencies. Likewise, Baran (2014) looked at trends in the mobile learning and teacher education literature from 2000 to 2014, nearly $38 \%$ of the research on mobile learning was conducted in the U.S.A teacher education contexts followed by Australia (3) and Finland (3). The same study reports mobile phones were the most common mobile devices used in teacher education contexts (42.5\%), followed by tablets (17.5\%), PDAs/Handheld PCs (17.5\%), iPods (10\%), and laptops (12.5\%).

In mobile and ubiquitous learning studies from 2001 to 2010, research samples in higher education were selected most, followed by elementary school students and high school students with relatively few studies selecting teachers, and working adults (Hwang and Tsai, 2011). Similarly, Wu et. Al. (2012) noticed that the number of mobile learners increased sharply after 2009 with mobile learning most frequently utilised by higher education students $(51.98 \%)$, followed by elementary school students (17.51\%), adult learners (12.43\%), secondary (post-secondary) school students $(8.47 \%)$ and disabled students $(0.56 \%)$. Conversly, Petrova and Chun (2009) found that participants usually involved students or other types of learners as appropriate to the context. However, participants from other groups (academics, the researchers themselves) acted as domain experts or usability testers.

The major contributing countries from 2001 to 2005 were US authors contributed the most publications followed by UK authors and Taiwanese authors (Hwang and Tsai, 2011). However, from 2005 to 2010 the number of Taiwan papers increased tenfold to 51 which may be due to the initiation of the government-backed mobile and ubiquitous learning project in 2007 (Chang et al., 2009). Of 164 studies from 2003 to 2010 evaluating the effects of mobile learning was 


\section{CAPTURING MOBILE COLLABORATION THROUGH THE TRIANGULATION OF}

QUALITATIVE AND QUANTITATIVE DATA

the most common research purpose $(58 \%)$, followed by designing a mobile system for learning $(32 \%)$, investigating the affective domain during mobile learning $(5 \%)$ and evaluating the influence of leaner characteristics in the mobile learning process $(5 \%)$ (Wu et al., 2012). In a 2009 review of 424 articles, Petrova and Chun (2009) found that the majority of reviewed publications explored the two already identified research domains of 'technology' and 'pedagogy,' often with the two areas covered in a single work and a number covering 'educational theory.' Of 164 studies published from 2003 to $2010,86 \%$ of studies reported positive research outcomes, while only $4 \%$ and $1 \%$ respectively reported neutral and negative outcomes (Wu et al., 2012).

\section{STUDY DESIGN}

The research design presented here is a case study to explore the impact of mobile phones on collaborative learning activities in a university setting. This section discusses issues related to the study theory, methodology, participants, ethics, and validity and reliability. The theoretical ideas underpinning the mixed methods in this case study is Activity Theory (AT). Based upon Vygotsky's socio-cultural psychology and Leontiev's developmental psychology (Pachler, 2010), AT posits that conscious learning emerges from activity, not as a Piaget (1952) stated a precursor to it. This provides us with an alternative way of viewing human thinking and activity (Jonassen and Rohrer-Murphy, 1999). AT is not a methodology but a "...philosophical framework for studying different forms of human praxis as developmental processes, both individual and social levels interlinked at the same time" (Kuutti, 1996) AT is a powerful and clarifying descriptive tool rather than a strongly predictive theory (Nardi, 1996).

The methodology utilised in this study can best be described as a longitudinal mixed methodology (qualitative and quantitative data), exploratory, multiple case study approach adopted for a period of one academic year. The objective was to gain a greater understanding of the processes and consequences that result from incorporating mobile phone interaction capabilities into collaborative learning activities for Japanese university undergraduates.

This study adopted an exploratory instrumental case design (Stake, 1995, Yin, 2009, Silverman, 2009) because the objective of the investigation was to understand how students utilise mobile technology for collaborative activities with an outcome that was unknown to the investigator. So the case was the unit of analysis and was defined by the phenomenon of collaborative activities in the bounded context (Miles and Huberman, 1994) of a course on translation studies. In order to avoid an overly broad focus, a common problem associated with case study research, boundaries were placed on the unit of analysis (Stake, 1995, Yin, 2009). That is, the cases were bound by time and activity (Stake, 1995, Creswell, 2007, Miles and Huberman, 1994). The time constraint was fixed at one academic year, and the activity constraint was confined to mobile collaborative activities.

Instead of the traditional single case design, this study adopted a multiple case study design (Stake, 1995, Yin, 2009) because the context, several separate but identical classes, of the study provided for several case studies simultaneously, and the added reliability was a considerable asset when considering the qualitative aspects of the investigation. Also, since a multiple case study permits a researcher to probe within each setting and across settings, it was more suitable for investigating the location independent nature of mobile learning. Each case was formed from students in a translation course that was divided into four separate classes identical in terms of level, administration, and content. One group was formed from each class to obtain four case study groups with between five to eight members. All course tasks and educational environmental factors remained consistent across the groups. 
IADIS International Journal on WWW/Internet

The participant sample in this study was drawn from a larger population of undergraduate students studying English as a foreign language at a four-year private university in Tokyo, Japan. The students were all between the ages of 18 and 20 years and living in Japan during the study period. Four groups of between five to eight members were formed from volunteers and followed a three-step process. First, fifty potential students taking a translation studies course were introduced to the research project during an orientation class. This course was partitioned into four distinct classes with a balanced mixture of student academic level. Interested students were asked their class to verify that they were in one of these translation classes and that their mobile phone could access the course mobile website to perform the online tasks required for the collaborative activities. These activity requirements included reading and posting mixed media messages to the website forum page. Second, brief conversations were conducted to finalise the sampling process. The preliminary criteria for student selection was arrived at from a review of literature (Song and Fox, 2008) and consisted of: a positive attitude towards technology use in general to increase the likelihood they would make routine use of the mobile technology to complete the tasks; an interest in their academic studies to ensure that they would be motivated to engage in the tasks; a continuous presence in Japan during the one academic year to minimise the risk of an interruption in data collection; nationality homogeneity focused the study on Japanese students; experience in operating the mobile phone functions to ensure that they could use the course website; that the mobile phone of all participants had access to the capabilities required by the website. A gender balance of males and females was attempted but was infeasible owing to the high percentage of female students in the school. Group one had 5 girls and 2 boys, group 2 had 8 girls, group 3 had 6 girls, and group 4 had 6 girls.

Ethical procedures were clearly stated to all participants. A consent letter, consisting of terms and conditions for participating in this project, was given to the participants. All participants had to make use of their personal smartphone. The participants acknowledged the potential mobile connection cost and only those students having fixed rate unlimited data transfer contracts with their service providers could participate. They were also informed that they may withdraw at any time without repercussions and that their participation would not affect their course grade. It was explained to them that they could access the website from any device including computer or any mobile device just as all non-study students. All data was stored in an encrypted form, and no personally identifiable information such as full name or institution were released.

Validity and reliability determine the value of any research findings. Construct validity is the identification of correct operational measures for the concept being studied. It was increased through the use of multiple sources of evidence and the establishment of a chain of evidence during the data collection phase (Yin, 2009). This study is concerned with mobile learning with a focus on collaborative learning; the specific measure is participant observations and interviews. Here the objective of the study is concerned with mobile education. The specific concept is collaborative learning which is related to the original object of mobile learning by concentrating on collaborative learning in mobile education. Mobile collaborative learning is in turn matched with the operational measure of participant observations and interviews. Internal validity applies to explanatory or causal studies only which seek to establish causal relations, but since this case study is not an explanatory one the discussion of internal validity will be limited. External validity is the definition of the domain to which a study's findings can be generalised and this study relied on analytical generalisation and not statistical generalisation (Yin, 2009) by generalising to a pre-existing theory which functions as the vehicle for examining other cases. Reliability demonstrates that the operations of a study can be replicated, so 


\section{CAPTURING MOBILE COLLABORATION THROUGH THE TRIANGULATION OF}

QUALITATIVE AND QUANTITATIVE DATA

represents the attempt to minimise errors and biases. In this study, reliability was enhanced by maintaining a database of all online actions(Yin, 2009). The data from each group was treated identically and the data collection process was identical across groups; the interviews shared the same location and duration.

\section{DATA COLLECTION}

This section deals with the data collection and analysis stages and includes explanations of the data collected, data collection process, and data analysis techniques. Evaluating mobile device use is challenging because of the wide variety of usage patterns (Trinder et al., 2009), locations, and circumstances, in which they are employed make it infeasible to follow the user around. When compared to laptops or fixed computers, mobile or pervasive technologies present a challenge to methodology designers (Lim and Rogers, 2008). For this reason, a range of both qualitative and quantitative data was gathered so as to provide a wide "net" with which to capture a diverse range of data.

Quantitative data collection followed van'T Hooft's (2009) proposed six types of quantitative research data for collection with mobile devices were followed; spatial data indicating where the device is being operated; temporal data indicating when the device is being used; user data showing what they are being employed for; learner data indicating what content is being accessed; connectivity data recording who the learner communicates with; assessment data which deals with how the learners know that they are learning and what they are learning. This study incorporated the collection of spatial data through a short survey done during each mobile log in, but no specific location coordinate data was collected. The website logs recorded temporal data of website entry and actions but could not resolve the precise time spent online. The online time was worked in as an interview question to obtain an approximate sense of how long the participants spent online during each activity. User data was gathered on the actions while logged into the research website to provide a coherent picture of how they carried out the activities. Also, the MDS data was collected to provide a visual representation of any changes in relationship between user and device in the context of the activities (Ilic, 2014). The learner data was recorded and included all online actions and artefacts related to the collaborative activity. The connectivity data was gathered solely for the forum post interaction logs, so any contact outside of the Moodle course website was not recorded in the website logs. The students could declare any alternative communication channels (Twitter, Facebook, face-to-face, etc.) employed each week by filling out their weekly E-Journal which is similar to log books used in some studies (Corlett et al., 2005). The course assessment data comprised the forum answers but was not part of this study because the researcher wished to separate any grading of student participants and the research.

Qualitative data generally consists of attitude surveys, interviews, and questionnaires which typically rely on memory after the event for developing theory and interpretations from the perspective of the individuals being studied (Ezzy, 2002). Theoretical questions and answers were continuously updated in an ongoing dialogue with the experience being investigated which in turn allowed for the transformation of interview questioning producing a much more sophisticated understanding of the experience under study (Ezzy, 2002). This process of examining the data as it is collected continued until a point of saturation had been attained where the researcher could find nothing new (Glaser and Strauss, 1967). 
IADIS International Journal on WWW/Internet

This account of qualitative data collection and analysis accurately describes those employed in this study. These include participant interviews, participant weekly e-journals, the immediate transcription and coding of data, the confirmation of interpretations with the participants, and the writing of researcher memos. A timeline of the major data collection periods can be seen in Figure 1. Student online website log data, e-journals, student artefacts, and face-to-face interviews comprised the principal sources of data. Retrospective interviews were also carried out to resolve the queries raised from preliminary examination of student e-journals, artefacts submitted such as posted comments to the website, and online logs. Triangulation was employed to strengthen the validity of findings by correlating data from these various sources and noting when they converged on a similar result (Mathison, 1988).

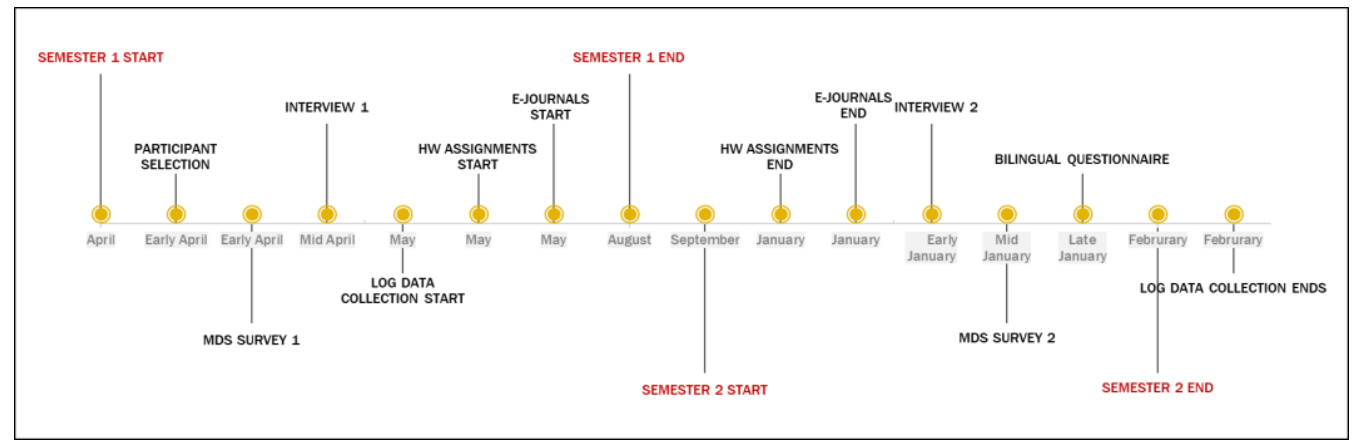

Figure 1. Study timeline

\subsection{Web Site Logs}

Several computer logging systems were employed to monitor the participants' interaction with the website. These logging systems enabled the researcher to distinguish interesting usage patterns that could be later correlated with the other findings. All initial entrance to the Moodle page went through Handset Detection service which distinguishes the entry device - mobile phone, tablet, computer, etc.- characteristics. Once the device is determined, the service feeds non-mobile devices directly to the Moodle site and mobile devices to the location survey. This survey has three choices of inside, travelling, and outside which provided an insight into a participant's general environmental context when they gained access to the system. Following this, the mobile traffic was tagged with the characters "MLE" (Mobile Learning Environment) before being recorded with the PiWik logging system which is a free online server logging software. Also, Google Analytics recorded the mobile traffic before it was feed into the main Moodle site. In the Moodle site, the internal logs recorded both non-mobile and mobile traffic. It was not technically feasible or ethical to geolocate a user by their Internet Protocol (IP) address, so there was no attempt to isolate the precise geographic location. When these logs are combined, they produced a detailed picture of the online activity. This integrate data allowed a straightforward triangulation and analysis of the data.

The main purpose of the logging was to better understand the mobile phone access patterns of the students. This necessitated a reliable means of separating mobile phone access data from computer access data. The capability to cross reference Moodle internet activity logs with the PiWik internet activity logs reduced the possibilities of confusing the two device types access 


\section{CAPTURING MOBILE COLLABORATION THROUGH THE TRIANGULATION OF}

QUALITATIVE AND QUANTITATIVE DATA

streams. While computer IP addresses are relatively constant over days, mobile IP addresses can vary by a few digits over minutes (Balakrishnan et al., 2009) which makes it necessary to cross reference the mobile data streams to follow the student's online activities. This consisted of locating mobile logins in the Moodle logs which had the "MLE" tag then that tagged IP address was paired with the identical PiWik log IP address using the shared data points of time, IP address, and the mobile entry page URL address of the entry location survey or the initial mobile entry page of Moodle. By tracing the flow of traffic forwards from the initial access along these two logged streams a highly reliable activity report was generated. The most useful logging system was the Moodle internal log as this was part of the content management system (CMS) itself. So this was used as the key system onto which the other logs were added. The PiWik logs were very important for isolating individual students and the Google logs help with identifying device types and OS versions which in turn help isolate individuals. A PERL or PHP program would have saved much time with the merging of the separate logs but was not developed and implemented due to time constraints.

\subsection{E-Journals and Questionnaire}

The e-journals and the final questionnaire proved to be rich sources of data. Many of the findings from the interviews and other data sources were corroborated through triangulation with the e-journals and questionnaire; this can be seen in Table 1. In addition, they provided a way to monitor back channel communications between students that took place outside of the course CMS. The e-journals contained the students' impressions of their collaborative activities throughout the year. A thorough explanation and demonstration was given on the writing of e-journals to the participants before the data collection was initiated. These e-journals were employed as introspective tools in the investigation, as they could provide the researcher access to the students' voices (Nunan, 1992). Students were requested to submit their reflective e-journals, which were accessed through the same Moodle online Learning Management System, once a week. The material gathered included several types of information; identification of the participant allowed for follow-up questions during interviews; inter-group communicateion methods employed outside of the Moodle system (face-to-face, voice phone call, email, class website mobile version, class website computer version, other social media sites such as facebook, and an option for 'Other') were included; a text field was added in which the students could write in their native language (Japanese) any impressions they had about the activities. 
IADIS International Journal on WWW/Internet

Also, once at the end of the study, a questionnaire containing open-ended questions was given to the students in which they were encouraged to express their opinions on the previous year's homework activities in their native language. This had two purposes; it permitted the lecturer to reflect on the activities to revise and refine the pedagogical value; it captured any final comments that the students wished to convey in greater detail without the burden of communicating in a second language.

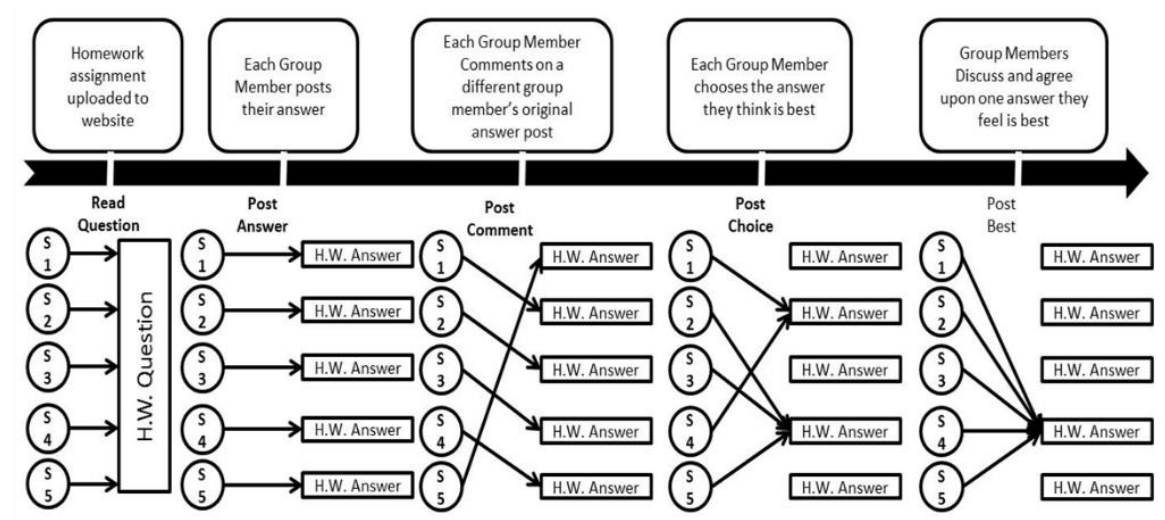

Figure 2. Homework workflow

\subsection{Artefacts}

Artefacts in this research refer to text, video, picture, audio, or any other files that students made while using their mobile phone. Some educational research studies of handheld devices have employed this approach as a means of data collection (Crowe and van't Hooft, 2006). Collecting student artefacts was an unobtrusive means of collecting information about how students took advantage of the mobile phone (Savenye and Robinson, 2004). The collaborative learning activity was presented around a computer based CMS called the Modular Object-Oriented Dynamic Learning Environment (Moodle) (Dougiamas, 1999). The primary form of these artefacts was the Moodle forum comments submitted by each student during the homework activity.

The activities used in this study was in the form of small group collaborative learning activities consisting of weekly modules that were accessible on private class website by either mobile phone or computer. These activities consisted of homework questions related to translation issues that are relevant when moving between the Japanese and English languages. The workflow of all homework assignments was identical and is shown in Figure 2. Prior to each of these activities the specific topic of the activity was discussed in the classroom and included theoretical concepts, terminology, and practical examples. The homework activities were all collaborative in the sense that they required the individual members of each group to find and upload their answers to the class website and then to decide upon a best single answer from their group answers. The members of each group communicated with the group as a whole by uploading a text message with or without some other media such as photographs to the website forum. All discussions were done outside of class and discussed in-depth in the following weeks class. 


\subsection{Interviews}

In this study, the purpose of the interviews was to obtain empirical knowledge of the participants. These were exploratory semi-structured interviews constrained by a conceptual and theoretical understanding of the topic developed during the literature review stage (Kvale and Brinkmann, 2009). Using semi-structured questions allowed for some focus on specific research questions while providing room for unexpected responses from the interviewees. The interviews were conducted in English which is the interviewees' second language.

Two semi-structured individual interviews were conducted over one academic year. The first was held at the tail end of the first semester; the intention was to obtain information on participant attitudes to using mobile phones and to ensure that they were completing the weekly homework activities without difficulty. The second interview was held at the end of the second semester and consisted of follow-up questions from the first interview and any clarification questions required to explain access patterns, journal comments, or any other points of interest. The interviews were 30 minutes long and face-to-face involving one interviewer and one interviewee at a time. After each interview was completed, the results were analysed so any new knowledge could be accumulated and then inform the generation of further probing and follow-up questions which feed back into following interviews. Each interview was recorded, transcribed and presented to the participants for their approval on accuracy. As suggested by Kvale et al. (2009), a work-journal was kept to record researcher insights, altered understands of previous experiences and reflections on the research process. The interview was transcribed and coded throughout to furnish an insight into the participants' thoughts as related to the research questions. The coding for this transcribed data was carried out in the NVIVO qualitative research software environment.

\section{DATA ANALYSIS}

\subsection{Qualitative Data Analysis}

The results of the coding process in this study is summarised in Table 1. The qualitative coding included the interviews, website logs, location survey, e-journals, questionnaire, and artefacts. The first stage of data analysis was content analysis, the organising, tracking, categorizing, and contextualizing the data obtained at distinct stages within QSR International's NVivo 10 Software to improve the reliability of the study (Yin, 2009, Stake, 1995, Maxwell, 1996, Wickham and Woods, 2005). A inductive form of thematic analysis coding (Ezzy, 2002) was adopted to identify themes or concepts in the data, build a systematic account of what has been observed, identify any emergent theory, and highlight issues and problems not anticipated. All interviews were transcribed immediately following the interview, so the transcription process served as a preliminary form of data analysis as it allowed for researcher reflection on the issues. This was the first cycle of coding were the data was coded through examining the interview transcripts word-by-word to search for in-vivo codes and looking for similarities and differences. This continued for all of the qualitative data sources collected. Then, second cycle coding required the researcher to classify, priorities, integrate, synthesis, abstract, conceptualise, and build theories. The principal objective of second cycle coding was to develop a sense of categorical, thematic, conceptual and/or theoretical organisation from the first cycle data 
IADIS International Journal on WWW/Internet

(Saldana, 2009). Each coding cycle included Open Coding, Axial Coding, and Theoretical Coding (Ezzy, 2002) and ended when the data was saturated; the analysis could produce no new codes or categories, and all the data was accounted for in the core categories. Open Coding generated the emergent set of categories and their properties and was followed by Axial Coding to integrate codes around central categories by specifying a category in terms of the conditions that created it, the context in which it is embedded, the interactional strategies by which it is managed, and the consequences of those strategies. Finally, Theoretical Coding involved the identification of the core category around which the analysis is focused (Table 1).

\subsection{Quantitative Data Analysis}

In this study, at the beginning and the end of the data collection period, the participants were given an online word association questionnaire to complete, and the results were analysed using a MDS technique. MDS is a method for capturing efficient information from observed dissimilarity data by representing the data structure in lower dimensional spatial space. The reasoning behind using this technique was that it could provide a picture of how students perceived mobile technology in relation to the other aspects of their school life within the context of the study. By comparing this image pre-study and post-study, any changes in their views may be observable. For this paper, MDS was also used to map the interaction of data types during the triangulation stage of data analysis as shown in Figure 3.

MDS is a well-known group of data analysis techniques which spatially represent the data's structure to make it easier to assimilate. There was only one previous examples of this techniques being used for the study of mobile learning (Ilic, 2015). However, there is a long history of the use of MDS for building, comparing and ranking, and visualising data in many areas of research (Nagino et al., 2008, Simon and Eby, 2003, Adams and Tracey, 2004, Bimler and Kirkland, 2001, Sireci and Geisinger, 1992, Maeda and Ritchie, 2003, DeJordy et al., 2007, Oltman and Stricker, 1990). In this study, the purpose for using MDS was to obtain a picture of the participants' relationship to school in general, homework, and mobile phones. It was expected that by analysing these word association questionnaires, the researcher could observe any variation in participant attitudes in the changing relational position of the words.

The data is numerical and in the form of symmetric similarity data consisting of student perceptions of the similarity among the following twenty-five English words: Afternoon, Alone, Computer, Dictionary, Discussions, Education, English, Evening, Groups, Home, Homework, Listening, Mobile Phone, Morning, Night, Outside, Picture, Reading, School, Speaking, Text, Travelling, Video, Voice, Writing. The word associations formed a 25 x 25 matrix of all possible word pairs. The participants were required to enter a value from 0 to 5 in the matrix cell at the intersection between each set of words which represented their perception of the strength of the relationship between the words. The participants were provided the following number to meaning relationships as a reference: $0=$ NO relationship, $1=$ very distant relationship, $2=$ distant relationship, $3=$ close relationship, $4=$ very close relationship, $5=$ extremely close relationship.

Two tables were produced: one for semester one and one for semester two. Each table represents the total of all values of relationship strength from 1 to 5 for each row word and column word pair. A higher number indicates a greater number of participants thought there was some amount of similarity between the word pairs. This type of data is proximity data which 


\section{CAPTURING MOBILE COLLABORATION THROUGH THE TRIANGULATION OF}

QUALITATIVE AND QUANTITATIVE DATA

consists of measures of similarity or dissimilarity between objects of interest (Everitt and Rabe-Hesketh, 1997). Here the objects of interest are the row words and the column words.

The output from MDS is in a two-dimension plot of all the objects (words), and the distance between them indicates the value of dissimilarity. The closer the words appear visually in the plot the stronger the participants' perceived similarity between them. The advantage of MDS is that it represents the data spatially to allow a visual interpretation of the distances between the points plotted in two dimensions, so the interpretation of distance is visual. As mentioned, there are two sets of data: one from semester one and one from semester two. These two data sets were combined into a super matrix which allowed any pre and post data change in perceived similarity value reported by the participants between the beginning and end of the study to be represented by a movement in the second set of plotted points. When a word is recorded as moving closer to another word, it indicates that the second semester data point has shifted closer to another second semester word, which suggests those two words are now perceived as having more in common at the end of the study than at the beginning. This information combined with the other data sources in this research enhanced the triangulation as can be seen in Table 1. Here we can see that the MDS results correlated around research questions one, two and three. In Figure 3, the MDS analysis is in cluster B along with "Interview 1", "Interview 2", and "Final Questionnaire" indicating that the findings from the original MDS analysis closely correlated with data from these three sources.

\subsection{Triangulation}

Many mobile learning research projects have utilised interviews, questionnaires, diaries, and focus groups to collect information (Sharples, 2009). When these methods are employed individually, in mobile research (Traxler, 2007) as well as other forms of research (Wali et al., 2009) there can be uncertainty in the reliance on the memory and honesty of participants. In this study, an additional problem with relying on users to articulate their actions is that they may not possess the English language skills to report their experiences. Triangulation is a research strategy that incorporates several such research methods in a single research study to yield a more comprehensive view, to clarify a complex phenomenon, or when a conventional approach generates a distorted picture (Cohen et al., 2007). Also, it can strengthen the validity of findings, such as when data from disparate sources or compiled with diverse methods "converge" (Mathison, 1988) on the same result.

There are two levels to methodological triangulation: between-method and within-method (Denzin, 1989). In this study student completion of collaborative activities through mobile phones was examined qualitatively by interviewing the participants and observing their response and quantitatively by comparing log data and conducting statistical analysis of survey data. However, the focus always remains that of applying mobile phones for collaborative activities, but the mode of data collection varies. The within-method is performed at the data collection level and entails the use of more than one data collection technique from within the same research tradition. The goal here is the replication of a study to check reliability and confirm theory (Cohen et al., 2007). In this study, this is represented in the varied participant observation data collected in multiple case study groups. At the data collection level, triangulation has been categorized into three types (Denzin, 1989) including time, space, and person; the researchers collect data at or from multiple times, locations, or human sources respectively. The investigation under discussion in this paper is a longitudinal study collecting continuous data samples from four separate groups over a one-year period, so both time and person data triangulation are utilised. 
IADIS International Journal on WWW/Internet

Table 1.Triangulation of Data and Findings

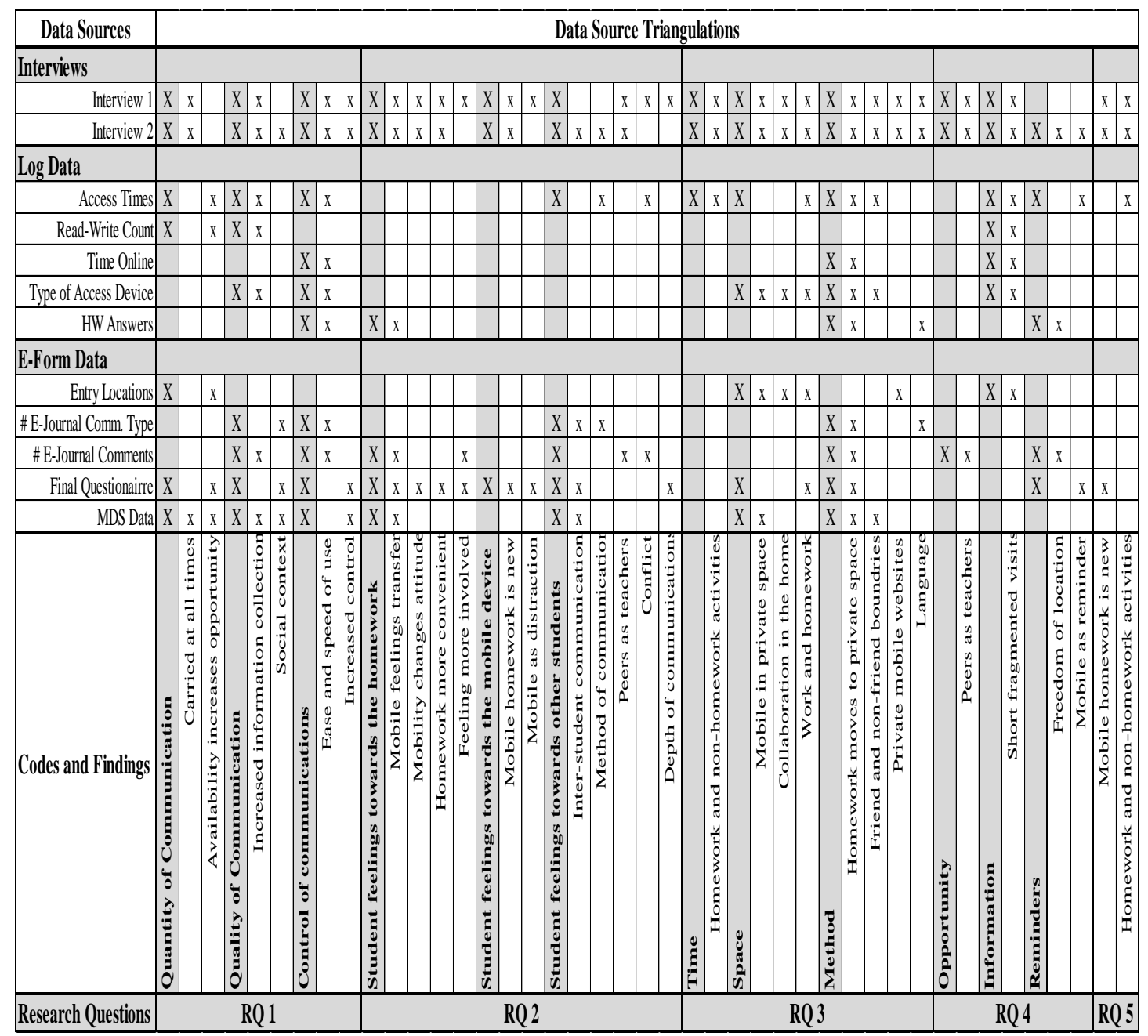




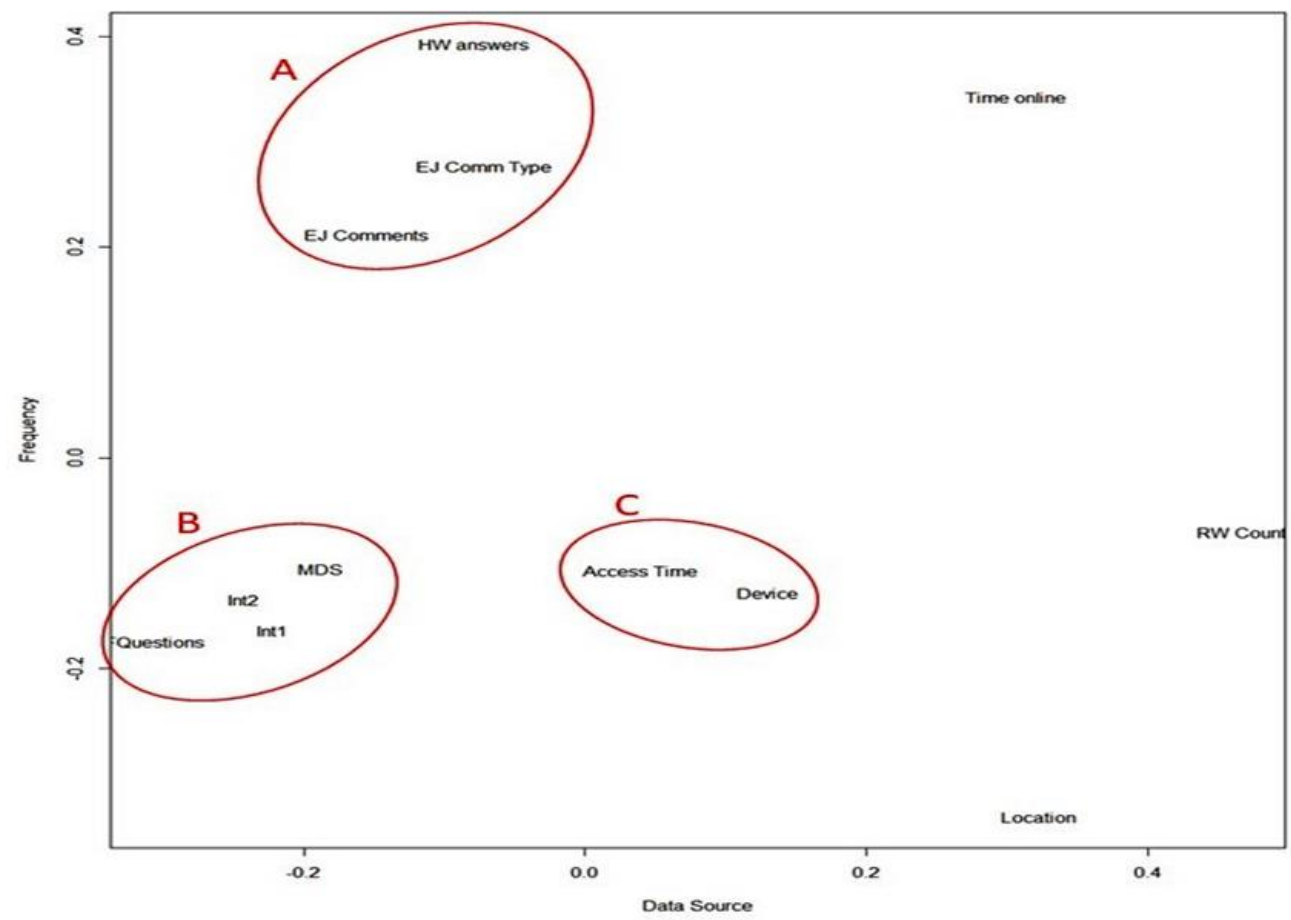

Figure 3. MDS Analysis of Data Triangulation

There are limitations to the within-methods approach to methodological triangulation because no matter how many approaches are used the research is affected by the limitations of the single research tradition (Mathison, 1988). Several shortcomings of triangulation research studies in general are identified by Jick (1979) including the difficulty of replicating multi-method designs, the overwhelming effect of the theoretical and conceptual quality of the research question on a study regardless of how many methods are employed, the tendency to bias the discussion in favour of the researchers preferred method, and frequently overlooked need to explicitly state and justify the strengths and weaknesses of each method used in the triangulation. Likewise, Blaikie (1991) and Silverman (1985) suggest that triangulation is inherently positivistic since data triangulation assumes that a single unit can be measured more than once. Some have also suggested that having multiple data sources, particularly qualitative data, does not ensure consistency or replication (Patton, 1980). Finally, there have been doubts raised that one investigator can corroborate another in investigator triangulation and that no two theories can provide a complete account of a phenomenon (Guba and Lincoln, 2005).

Returning to the study under discussion, Table 1 contains a summary of how the data from the varied sources in this study were triangulated to support the key findings. The column on the left lists the types of data collection methods discussed above. Along the bottom are the key findings (grey cells) and supporting codes (white cells) pulled from the data separated by research question. An $x$ corresponds to the use of a data source to support the code which in turn supports the key finding for each research question. For example, in research question one, interview one, interview two, and the MDS analysis provided data for the coding of "carried all the time" which supported the finding that "quantity of communication" was affected by the use 
IADIS International Journal on WWW/Internet

of mobile devices. So, in this example, three separate sources were triangulated to strengthen the claim for this code. The chart shows that across all of the codes, for any single code there was a minimum of two and a maximum of 10 discrete data sources supporting that code.

The value of the triangulation is clear from large number of supporting data points for each code represented in Table 1. The data points are both qualitative and quantitative so supporting the idea that mixed methodology studies can provide a rich multidimensional view of a complex collaborative activity such as mobile learning. The clarify this point, in Figure 3 this same data has been analysed using MDS to produce a two-dimensional plot of the triangulation data in Figure 3. MDS Analysis of Data Triangulation. In this plot, the distance between the data sources represents the similarity - the number of times the data sources supported each other. There are three clear outliers; these include "Time online", Read Write Count, and "Location." "Time online" can be explained by the technical difficulties in measuring mobile connect time as discussed earlier. This made the data source unreliable alone which made the researcher hesitant to use it. "Location" data was collected from the small three-question survey the students were to answer each time they connected to the mobile website. However, it was found through the interviews that many students set bookmarks for the mobile site which linked to internal pages of the website so bypassing the small location survey. This again meant that the data was not utilised to a great extent because the number of student answers was limited. The "RW Count" (read/write count) was accurately measured but appears to have had little impact on the triangulation of data. This may have been an oversight on the part of the researcher or could mean that the data was of little value. This could be an area for further research.

Cluster A includes "Homework Answers", E-Journal Communication Types", and "E-Journal Comments". One possible explanation for this cluster is that this data was collected on a weekly basis at the same time as the homework activities. This means that the issues directly related to homework completion and submission would likely appear in these three sources. If a participant had trouble with a homework discussion online, they would likely mention it in their weekly E-Journal along with the type of problem -face-to-face, texting, etc. This can be seen in Table 1 with the code "ease and speed of use" which is supported by these same three sources. Cluster B includes "MDS Analysis", "Interview 1", "Interview 2", and "Final Questionnaire." These four sources were clearly separate from the course in which the homework assignments were completed. Without the final questionnaire these took place twice during the research which may account for the similarity of topics. Also, they were heavily affected by the researcher reflections during the ongoing process of exploratory research. The interviews and the final questionnaire provided a way to collect the participants' detailed views of the experience of working with the mobile devices. An example of this is the code "increased control" under research question one.

These results suggest that separate forms of data collected at similar frequencies and times may increase the likelihood of triangulating those data. Again, this can be seen as evidence for the importance of various data collection cycles within a single research study. Cluster A was a weekly collection cycle and the three types of data collected clearly supported each other. The same can be seen for the yearly collection cycle in cluster B. The distance between these clusters indicates that there were fewer triangulated data points between the clusters then there was within them. One question that must be asked is whether this reduced triangulation between cluster A and cluster B data sources is due to differences in data findings alone or researcher actions. The coding phase of the research involves several iterations to isolate the codes, but this result suggests that a deeper comparison of the findings between these two clusters may yield another layer of codes. 


\section{CAPTURING MOBILE COLLABORATION THROUGH THE TRIANGULATION OF}

QUALITATIVE AND QUANTITATIVE DATA

\section{FINDINGS}

In this section are summarised the key findings of the investigation that culminated from this methodology and are organised by research question. The results are present in such a way as to highlight the benefits of triangulating several mixed data sources. Since this paper concentrates on the methods, so the findings are only briefly described and will be discussed in more detail in a subsiquent publication. However, the following findings and triangulation of multiple data sources are summarised in Table 1.

This study sought to answer the research question: "How do students complete collaborative learning activities with mobile phones?" This question is a broad overarching one answered through five sub-questions. These five questions focus on these facets of mobile learning for collaboration: affordances, affective, intervention, awareness, and dialogue.

The initial question asked what distinctive affordances are offered by the mobile phone for collaborative learning. It was found that the students employed mobile phones to increase the frequency of contact with the homework and their collaborative group members, creating an opportunity for seamless learning. Students suggested that this shift in the quantity of communication, may be due to the physical size and continual availability of the mobile devices as compared to computers which led to an escalation in the contact; by carrying the device at all times, its availability increases the opportunity for access. They also reported that the mobile phone is a robust data collection and storage tool that is discreet enough to fit any social situation which supports collaboration. This change in the quality of communication appeared in many forms and included multimodal data collection in a variety of media formats that could be uploaded to enhance text only homework discussions. Also, it was reported that the discrete nature of the device and availability allowed it to be used in a variety of social situations at school and outside of school. This question also led to the finding that the students have better control over their collaboration when using a mobile phone alone or in addition to other communication systems. The students reported that increased control through the availability of the communication device supports them whenever they wish to engage in the collaboration. This enhanced freedom of communication was commonly described as an increase in ease of use, speed of use, and flow of information when compared to other options. So, the enhanced control of communications owing to the ease and speed of mobile phone use seems to have increased each participant's control of how they collaborated.

The second question focuses on the affective relationship between student the mobile phone and the homework. One finding was that the students' use of the mobile phone allowed the popularity of the device to influence their feelings towards the homework. The students reported that increased access to the opinions of others through the collaborative activities gave them a greater opportunity to examine their own values and preferences by reflecting on the comments of other group members. The relationship that the students have towards the homework can be viewed in a range of forms and includes the student using the mobile phone to do the homework activities and the group employing the mobile phone to complete the activities. This may be due to the interactive nature of collaborative activities, but the increased media options offered by the mobile devices over simple face-to-face communication were reported to have enhanced this reflection. The students reported that feelings towards the homework were influenced by those they had hitherto held for the mobile phone in terms of positive attitude of the device, convenience of the device, and other feelings. Another finding was that the students' use of the mobile phone as a means for collaboration changed the perceived value of the device. The 
IADIS International Journal on WWW/Internet

feelings towards the mobile device were noticeable when they employed it for homework and included negative feelings. Using the mobile phone for homework was new for them, and some saw it as a distraction from the homework. This question also indicated that the students altered their view of other students in their group after adopting the mobile phone for collaboration activities. The changes appeared in many forms and included relationship, support, and some negative feelings. These changes were observed in the inter-student communications, method of communication, peers acting as teachers, conflict between students, and the depth of communications.

The third question looked at whether the intervention affected the relationship between students, their mobile phones, and their homework. It was found that the mobile phone encroached on private time that would otherwise not have been applied for homework collaboration. These times included that spent commuting, doing daily activities, and socialising. This led to homework and non-homework activities merging where they had not previously. This question also indicated that the students brought the homework into places in which they had either infrequently or never performed this type of collaborative homework. This development in the type of spaces in which collaboration took place was observable included mobile as a private device, home as a place for homework, and work as a place for homework. Also, the position of the mobile phone as a fundamental communication device and the capability to shift freely between the private websites and the public homework website it affords places the device as a bridge between the public and private life. This was observable in a range of forms and included feelings towards mobile device, non-friends, private websites, and language. Homework moved farther into private space of students, friend and non-friend boundaries were blurred, private mobile websites started to be utilised, and language used for communications varied.

The fourth question sought to discover whether the affordance offered by the technology leads to higher awareness of learning. This question indicated the increased opportunity for reflection was due to the ability of the student to use short fragments of time previously unavailable. Also, the students have an unbroken link to material provided by the instructor and their peers which supports the development of understanding, encourages discussion, exposes them to different points of view, challenges them, and increases reflection. In addition, the students reported that the mobile phone as a tool for collaboration became a constant reminder of the homework. The reminders provided by the mobile device included freedom of location and the mobile device itself.

The fifth and final question considered the nature of the dialogue the students had with the mobile phone technology. This question is broad, so it was not expected this research could furnish a complete answer. The research indicates there is a dialogue with the technology and that it is characterised by a transition away from the traditional view of homework held by the students. This could be observed in the students' view that the mobile homework was something modern.

\subsection{Limitations}

The participants in this study were restricted to Japanese language speakers studying English as a second language. These students all grew up in a relatively wealthy densely populated urban area and were very familiar with mobile phones. These characteristics suggest this sample of students very homogeneous so the findings may not apply to students who do not share these 


\section{CAPTURING MOBILE COLLABORATION THROUGH THE TRIANGULATION OF}

QUALITATIVE AND QUANTITATIVE DATA

characteristics. Also, this study successfully utilised a CMS for mobile collaborative activities. However, this system was not originally designed to be used with mobile phones, so many system features were not available to the instructor when designing the activities. A system that utilised a mobile application, or app, as an interface for a CMS designed to accommodate both computer and mobile access would have allowed greater freedom in activity design and more definition in data collection. If an app was the main interface with the collaborative activities, the time students spent working on an assignment could be more accurately measured as it would be equal to the time the app was open and active on the smartphone. In addition, the standard 60 second system was used instead of the server time as the main log timing. In future studies it is recommended that the server time be used as it is more accurate. Concerning the short location entry survey, it was used in place of a true coordinate system because of technical limitations. This data would be more valuable if the researcher had secured permission to collect true Global Positioning System coordinates which could not be bypassed by bookmarked links as was the case in this study.

The log data formed a crucial part of this methodology by providing a precise picture of student activity, but the process of combining the multiple logging systems should be done with software to decrease the amount of time needed to combine the logs; The PERL and PHP scripting languages would be useful here. The use of the super matrix MDS analysis was very valuable in providing a graphic representation of the changing attitudes of students over the length of the study. The MDS analysis used in this study was limited to 2 dimensions so it would be interesting to extend this research and analyse the data using a 3-dimension plotting which my provide further in information.

\section{CONCLUSION}

This research study provides several implications for further mobile learning research. In terms of methodology related recommendations that may overcome issues with mobile data collection and mobile interface. The results suggest that separate forms of data collected at similar frequencies and times increases the likelihood of triangulating data points so compensates for the difficulties related with studying this fluid phenomenon. This can be seen as evidence for the importance of various data collection cycles within a single mobile research study. The researcher feels that these multiple data sources and case study design did add to the validity and reliability of the findings in this research by providing many points of data triangulation. The difficult of studying a phenomenon of this type that takes place at all times of the day and in all imaginable spaces is clear. The log data provided an invaluable source of confirmation for the interview data and the MDS plot provided a further graphic representation that greatly help in identifying changes that correlated across data sources. However, an even clear picture is formed when all of these data sources are triangulated.

In the future, the relationship to the mobile phones and the position they hold in student lives could be better understood through another a series of longitudinal studies following the same methodology. Since the relationship that students have with technology changes as fast as the technology advances, this could include a new cohort of students each year for several years. Each progressive year will have had a different history with the technology, and it is this slight difference that could provide important insights on the relationship between mobile device affordances and learning. 
IADIS International Journal on WWW/Internet

\section{REFERENCES}

Adams, R. S. \& Tracey, T. J. 2004. Three versions of the Interpersonal Adjective Scales and their fit to the circumplex model. Assessment, 11, 263-270.

Balakrishnan, M., Mohomed, I. \& Ramasubramanian, V. Where's that phone?: geolocating IP addresses on $3 \mathrm{G}$ networks. Proceedings of the 9th ACM SIGCOMM conference on Internet measurement conference, 2009. ACM, 294-300.

Baran, E. 2014. A review of research on mobile learning in teacher education. Journal of Educational Technology \& Society, 17, 17.

Bimler, D. \& Kirkland, J. 2001. School truants and truancy motivation sorted out with multidimensional scaling. Journal of Adolescent Research, 16, 75-102.

Blaikie, N. W. H. 1991. A critique of the use of triangulation in social research. Quality and Quantity, 25, 115-136.

Chang, M., Chin-Yeh, W. \& Gwo-Dong, C. 2009. National program for e-Learning in Taiwan. Journal of Educational Technology \& Society, 12, 5.

Cohen, L., Manion, L. \& Morrison, K. 2007. Research methods in education, London ; New York, Routledge.

Corlett, D., Sharples, M., Bull, S. \& Chan, T. 2005. Evaluation of a mobile learning organiser for university students. Journal of Computer Assisted Learning, 21, 162-170.

Creswell, J. W. 2007. Qualitative inquiry \& research design : choosing among five approaches, London, SAGE.

Crowe, A. \& Van't Hooft, M. 2006. Technology and the prospective teacher: Exploring the use of the TI-83 handheld devices in social studies education. Contemporary Issues in Technology and Teacher Education, 6, 99-119.

Dejordy, R., Borgatti, S. P., Roussin, C. \& Halgin, D. S. 2007. Visualizing proximity data. Field Methods, 19, 239-263.

Denzin, N. K. 1989. The research act : a theoretical introduction to sociological methods, Englewood Cliffs, N.J., Prentice Hall.

Dougiamas, M. 1999. Moodle [Online]. Available: http://moodle.org [Accessed].

Everitt, B. \& Rabe-Hesketh, S. 1997. The analysis of proximity data, London, Arnold ;J. Wiley.

Ezzy, D. 2002. Qualitative analysis : practice and innovation, London, Routledge.

Glaser, B. G. \& Strauss, A. L. 1967. The discovery of grounded theory; strategies for qualitative research, Chicago,, Aldine Pub. Co.

Guba, E. G. \& Lincoln, Y. S. 2005. Paradigmatic controversies, contradictions, and emerging confluences, In The Sage Handbook of Qualitative Research, Thousand Oaks, Sage.

Hooft, M. V. T. 2009. Researching Informal and Mobile Learning: Leaveraging the Right Resources. In: Vavoula, G., Pachler, N. \& Kukulska-Hume, A. (eds.) Researching Mobile Learning. Bern: Peter Lang.

Hwang, G.-J. \& Tsai, C.-C. 2011. Research trends in mobile and ubiquitous learning: a review of publications in selected journals from 2001 to 2010. British Journal of Educational Technology, 42, E65-E70.

Ilic, P. 2014. The Relationship between Students, Mobile Phones and Their Homework. In: Kalz, M., Bayyurt, Y. \& Specht, M. (eds.) Mobile as a Mainstream - Towards Future Challenges in Mobile Learning. Springer International Publishing.

Ilic, P. 2015. The Effects of Mobile Collaborative Activities in a Second Language Course. International Journal of Mobile and Blended Learning (IJMBL), 7, 16-37. 


\section{CAPTURING MOBILE COLLABORATION THROUGH THE TRIANGULATION OF}

QUALITATIVE AND QUANTITATIVE DATA

Jick, T. D. 1979. Mixing Qualitative and Quantitative Methods: Triangulation in Action. Administrative Science Quarterly, 24, 602-611.

Jonassen, D. H. \& Rohrer-Murphy, L. 1999. Activity Theory as a Framework for Designing Constructivist Learning Environments. Educational Technology Research and Development, 47, 61-79.

Kuutti, K. 1996. Activity Theory as a Potential Framework for Human-Computer Interaction Research. In: Nardi, B. A. (ed.) Context and consciousness : activity theory and human-computer interaction. Cambridge, Mass.: MIT Press.

Kvale, S. \& Brinkmann, S. 2009. InterViews : learning the craft of qualitative research interviewing, Thousand Oaks ; London., Sage Publications.

Lim, Y.-K. \& Rogers, Y. 2008. A Framework and an Environment for Collaborative Analysis of User Experience. International Journal of Human-Computer Interaction, 24, 529-555.

Maeda, E. \& Ritchie, L. D. 2003. The concept of shinyuu in Japan: A replication of and comparison to Cole and Bradac's study on US friendship. Journal of Social and Personal Relationships, 20, 579-598.

Mathison, S. 1988. Why Triangulate? Educational Researcher, 17, 13-17.

Maxwell, J. A. 1996. Qualitative research design: an interactive approach, Thousand Oaks, Calif, Sage.

Miles, M. B. \& Huberman, A. M. 1994. Qualitative data analysis : an expanded sourcebook, Thousand Oaks, Calif. ; London, Sage.

Nagino, G., Shozakai, M., Tomoki, T., Saruwatari, H. \& Shikano, K. 2008. Building an effective speech corpus by utilizing statistical multidimensional scaling method. IEICE TRANSACTIONS on Information and Systems, 91, 607-614.

Nardi, B. A. 1996. Studying Context: A Comparison of Activity Theory, Situated Action Models, and Distributed Cognition. In: NARDI, B. A. (ed.) Context and consciousness : activity theory and human-computer interaction. Cambridge, Mass.: MIT Press.

Nunan, D. 1992. Research methods in language learning, Cambridge University Press

Oltman, P. K. \& Stricker, L. J. 1990. Developing homogeneous TOEFL scales by multidimensional scaling. Language Testing, 7, 1-12.

Pachler, N. 2010. Mobile learning : structures, agency, practices, New York, Springer.

Patton, M. Q. 1980. Qualitative evaluation methods, Beverly Hills, Sage Publications.

Petrova, K. \& LI, C. 2009. Focus and setting in mobile learning research: A review of the literature Communications of the IBIMA, 10, 219 - 226.

Piaget, J. 1952. The origins of intelligence in the child (M. Cook, Trans.). London: Routledge\& Kegan Paul.(Original work published 1936) PiagetThe origins of intelligence in the child1952.

Saldana, J. 2009. The coding manual for qualitative researchers, Thousand Oaks, CA, Sage.

savenye, w. c. \& robinson, R. S. 2004. Qualitative research issues and methods: An introduction for educational technology. In: Jonassen, D. H. (ed.) Handbook of research on educational communications and technology. Mahwah, N.J: Lawrence Erlbaum.

Sharples, M. 2009. Methods for evaluating mobile learning. In: Vavoula, G., Pachler, N. \& Kukulska-Hulme, A. (eds.) Researching Mobile Learning. Oxford: Peter Lang.

Silverman, D. 1985. Qualitative methodology and sociology : describing the social world, Aldershot, Hants, England ; Brookfield, Vt., U.S.A., Gower Pub. Co.

Silverman, D. 2009. Doing qualitative research, Thousand Oaks, CA, Sage Publications.

Simon, S. A. \& Eby, L. T. 2003. A typology of negative mentoring experiences: A multidimensional scaling study. Human Relations, 56, 1083-1106.

Sireci, S. G. \& Geisinger, K. F. 1992. Analyzing test content using cluster analysis and multidimensional scaling. Applied Psychological Measurement, 16, 17-31.

Song, Y. \& Fox, R. 2008. Using PDA for undergraduate student incidental vocabulary testing. ReCALL 20, 290-314. 
IADIS International Journal on WWW/Internet

Stake, R. E. 1995. The art of case study research, Thousand Oaks ; London, Sage Publications.

Traxler, J. 2007. Defining, Discussing and Evaluating Mobile Learning: The moving finger writes and having writ. The International Review of Research in Open and Distance Learning, 8.

Trinder, J., Roy, S. \& Magill, J. 2009. Using Automated Loggingto Collect Information on Mobile Usage for Learning. In: Vavoula, G., Pachler, N. \& Kukulska-Hume, A. (eds.) Researching Mobile Learning. Bern: Peter Lang.

Wali, E., Oliver, M. \& Winters, N. 2009. Are They Doing What They Think They're Doing?: Tracking and Triangulating Students' Learning Activities and Self Reports. In: Pachler, N., Kukulska-Hulme, A. \& Vavoula, G. (eds.) researching Mobile Learning. Oxford: Peter Lang.

Wickham, M. \& Woods, M. 2005. Reflecting on the strategic use of CAQDAS to manage and report on the qualitative research process. The Qualitative Report, 10, 687-702.

Wu, W.-H., Jim Wu, Y.-C., Chen, C.-Y., Kao, H.-Y., Lin, C.-H. \& Huang, S.-H. 2012. Review of trends from mobile learning studies: A meta-analysis. Computers \& Education, 59, 817-827.

Yin, R. K. 2009. Case study research : design and methods, Los Angeles, Calif., Sage Publications. 